\title{
Estimation of the immigration time of Scirtothrips dorsalis Hood (Thysanoptera: Thripidae) adults in citrus orchards as a function of the total effective temperature
}

\author{
Shinichi MasuI ${ }^{\dagger}$ \\ Shizuoka Plant Protection Center; Iwata, Shizuoka 438-0803, Japan \\ (Received 1 February 2008; Accepted 12 May 2008)
}

\begin{abstract}
Scirtothrips dorsalis adults generally immigrate into citrus orchards immediately after emerging from other suitable host plants surrounding the orchards; however, a method to predict adult immigration time has not yet been established. In this study, I examined the relationship between immigration time and total effective temperature for $S$. dorsalis using trap data collected every few days. The investigation was performed in eight citrus orchards in Shizuoka Prefecture from early May to mid-September in 1999, 2000, and 2001. The total effective temperature was calculated using data from meteorological stations located near the orchards. In each orchard, a positive linear relationship was observed between total effective temperature $(y)$ and the generation number $(x)$ at each immigration peak. The slope and $y$-intercept of the regression lines did not differ significantly among five orchards in the central district of Shizuoka Prefecture; after pooling the entire data, the linear relationship could be expressed as $y=70.67+314.92 x$ $\left(n=84, r^{2}=0.989, p<0.001\right)$. In two of the three orchards in the western district of Shizuoka Prefecture, the regression lines did not differ significantly in their slope (using the same equation form).
\end{abstract}

Key words: Scirtothrips dorsalis; citrus; total effective temperature; immigration; insect trap

\section{INTRODUCTION}

Scirtothrips dorsalis Hood, commonly known as the yellow tea thrips, produces seven or eight generations every year in Shizuoka Prefecture, Japan (Sakakibara and Nishigaki, 1988; Tatara, 1994). The species is one of the most serious economic pests of citrus plants because large numbers of adults immigrate into citrus orchards from host plants surrounding the orchards (Tatara, 1994; Masui, 2007a) and damage the fruit surface during a long period, typically from June to October (Nishino and Kodomari, 1988; Tatara and Furuhashi, 1992). To control $S$. dorsalis infestations, insecticides are sprayed periodically (four to five times from June to September) during the period when the adults generally immigrate into the orchards. Yellow sticky traps are used to monitor the abundance of adult thrips in the orchards to provide guidance on the optimal timing of the sprays
(Ohkubo, 1989; Muraoka, 1990; Masui et al., 1995; Tatara, 1995). However, because it is often difficult to predict the time of adult immigration using these traps, control of the thrips is frequently unsuccessful.

Scirtothrips dorsalis overwinters in the adult stage (Okada and Kudo, 1982; Shibao et al., 1991), and overwintering adults start to lay eggs simultaneously in late March or early April (Masui, 2007b). This suggests that the developmental stage of the individuals has little variation in the spring and that the total effective temperature could potentially be used to forecast the time of adult emergence in each generation. Previous research has shown that the first three peaks of adult occurrence, including that of the overwintering generation from March to June, can be estimated by calculating the total effective temperature from January 1 in citrus orchards (Tatara, 1994) and vineyards (Shibao, 1996). However the subsequent four

\footnotetext{
${ }^{\dagger}$ Present address: Shizuoka Research Institute of Agriculture and Forestry, Iwata, Shizuoka 438-0803, Japan. E-mail: shinichi1_masui@pref. shizuoka.lg.jp

DOI: $10.1303 /$ aez.2008.511
} 
or five peaks, which reflect the generations from July to October, have been left unexamined. Thus, in this study, I examined the possibility of predicting the immigration time of adult $S$. dorsalis into citrus orchards both before and after June by calculating the total effective temperature.

\section{MATERIALS AND METHODS}

Study site. The investigation was carried out in five citrus orchards (Fuji, Shimizu, Shizuoka, Fujieda, and Haibara) in the central district of Shizuoka Prefecture and three citrus orchards (Iwata, Hosoe, and Mikkabi) in the western district (Fig. 1). Pesticides were applied following the conventional approach in each orchard.

Peak days of adult immigration. A yellow sticky trap designed by Muraoka (1990) was used to monitor adult abundance in each orchard from 1999 to 2001. A flat yellow (6.5Y 8.5/15.0 according to the Munsell Color System) polyvinyl chloride plate $(20 \times 20 \mathrm{~cm})$ covered on both sides by transparent sticky sheets $(20 \times 15 \mathrm{~cm})$ was placed vertically at a height of $1.5 \mathrm{~m}$ in each orchard. The number of adults captured by the trap was counted every few days from early March to mid-September. The traps were changed before $0900 \mathrm{~h}$ or after $1600 \mathrm{~h}$, during the period when few adults fly (Okada et al., 1981; Tatara, 1995). The mean number of adults captured per day in each trap was calculated by dividing the total catch by the number of days during which the trap was exposed. A 5-d moving average of trap data was calculated to identify the peak days of trap catch.

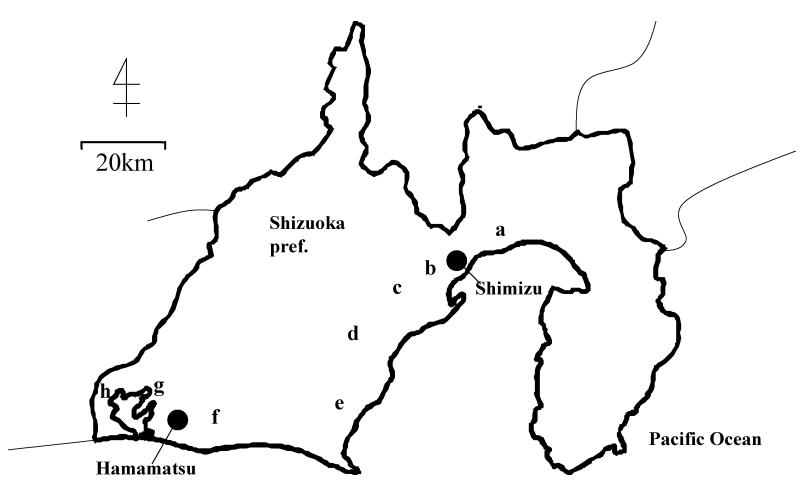

Fig. 1. Map of Shizuoka Prefecture showing the location of experiment orchards $(\mathrm{a}-\mathrm{h})$ and the meteorological stations (•). a, Fuji; b, Shimizu; c, Shizuoka; d, Fujieda; e, Haibara; f, Iwata; g, Hosoe; and h, Mikkabi.
Calculation of total effective temperature. Based on the report of Tatara (1994), the developmental zero temperature and the maximum temperature threshold for the development of $S$. dorsalis were fixed at 9.7 and $33.0^{\circ} \mathrm{C}$, respectively. The effective temperature for $1 \mathrm{~d}$ was calculated using the following equation:

$$
H(T i)=\left(\sum T i\right) / 24
$$

where $T i$ represents the effective temperature for every hour during the monitoring period; $T i=0$ $(t \leq 9.7), \quad T i=t-9.7 \quad(9.7 \leq t<33.0)$, or $T i=23.3$ ( $t \geq 33.0)$; and $t$ represents the temperature recorded at intervals of $1 \mathrm{~h}$. The total effective temperature $(H)$ was calculated by summation of the $H(T i)$ values obtained from January 1. The total effective temperatures in the five orchards in the central district and the three orchards in the western district were calculated using data provided by Automated Meteorological Data Acquisition System (AMeDAS) stations in Shimizu $\left(35^{\circ} 03.2^{\prime} \mathrm{N}\right.$, $\left.138^{\circ} 31.3^{\prime} \mathrm{E}\right)$ and Hamamatsu $\left(34^{\circ} 42.5^{\prime} \mathrm{N}, 137^{\circ}\right.$ 43.1'E), respectively (Fig. 1).

Data analysis. Simple regression analysis was used to determine the relationship between the total effective temperature $(y)$ and the generation number $(x)$. The generation number was estimated from the days of peak trap catches. The differences in slopes and $y$-intercepts of the regressions among the orchards were examined by means of analysis of covariance (ANCOVA).

\section{RESULTS}

\section{Peak days of adult immigration}

The seasonal changes in the number of $S$. dorsalis captured in the citrus orchards are presented, along with the total effective temperature, in Fig. 2. Although the patterns of trap catches differed among the orchards and years, the peak days of the trap catches were consistent. The numbers of adults captured in the 1st and 2nd generations peaked when the total effective temperatures reached approximately 400 and 700 degree-days, respectively; this result was consistent with that reported by Tatara (1994). Additionally, in each orchard, peak days were detected at intervals of approximately 300 degree-days after the 2 nd generation. In total, six peaks (i.e., six generations) were 


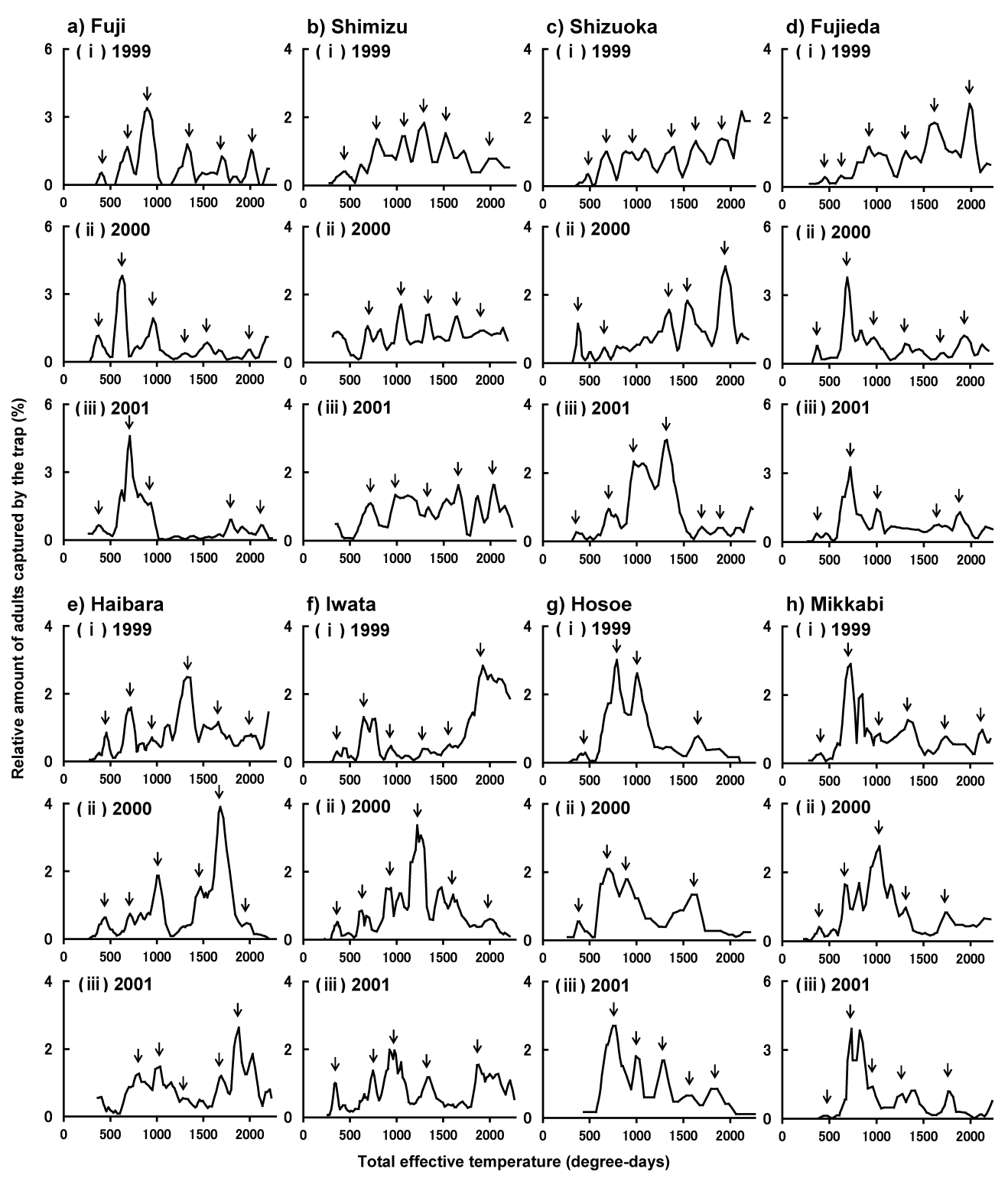

Fig. 2. Seasonal changes in the number of $S$. dorsalis adults captured in the sticky trap in the citrus orchards in relation to the total effective temperature accumulated from January 1. Arrows indicate the peak days of trap catch.

detected by the time the total effective temperature reached 2,200 degree-days, except in some cases wherein the peaks were obscured because of low abundance (e.g., in most orchards in 2001). Although the sex ratio of the captured adults fluctuated during the research period, no difference in the peak days was observed between male and female thrips. The exact dates of the peak days of adult immigration into each citrus orchard in each generation are presented in Table 1.

\section{Total effective temperature on peak days of adult immigration}

A positive linear relationship was observed between the total effective temperature $(y)$ and the generation number $(x)$ for each immigration peak in each orchard (Fig. 3: $n=13$ to $17, r^{2}=0.987$ to $0.994, p<0.001)$. The regression lines did not differ significantly among the five orchards (Fuji, Shimizu, Shizuoka, Fujieda, and Haibara) in the central district in terms of their slope (ANCOVA, $F=2.346, p=0.062$ ) and $y$-intercept (ANCOVA, $F=1.581, p=0.188)$. This result indicates that the 
Table 1. The peak days in trap catches of $S$. dorsalis adults in citrus orchards and the total effective temperature

\begin{tabular}{|c|c|c|c|c|c|c|c|c|c|c|c|c|c|c|}
\hline & \multirow{2}{*}{ Site } & \multirow{2}{*}{ Year } & \multicolumn{6}{|c|}{ Date } & \multicolumn{6}{|c|}{ Total effective temperature (DD) } \\
\hline & & & $1 \mathrm{st}$ & $2 \mathrm{nd}$ & $3 \mathrm{rd}$ & 4 th & 5 th & 6 th & $1 \mathrm{st}$ & 2nd & $3 \mathrm{rd}$ & 4th & 5 th & 6th \\
\hline \multirow[t]{3}{*}{ a) } & Fuji & 1999 & $5 / 17$ & $6 / 12$ & $6 / 29$ & $7 / 27$ & $8 / 17$ & $9 / 4$ & 399 & 683 & 894 & 1,325 & 1,696 & 2,013 \\
\hline & & 2000 & $5 / 16$ & $6 / 8$ & $7 / 4$ & $7 / 25$ & $8 / 8$ & $9 / 3$ & 374 & 630 & 960 & 1,305 & 1,544 & 2,003 \\
\hline & & 2001 & $5 / 15$ & $6 / 14$ & $6 / 30$ & - & $8 / 19$ & $9 / 8$ & 376 & 710 & 933 & - & 1,799 & 2,117 \\
\hline \multirow[t]{3}{*}{ b) } & Shimizu & 1999 & $5 / 22$ & $6 / 20$ & $7 / 12$ & $7 / 25$ & $8 / 7$ & $9 / 4$ & 449 & 784 & 1,072 & 1,290 & 1,522 & 2,013 \\
\hline & & 2000 & N.D. & $6 / 14$ & $7 / 10$ & $7 / 28$ & $8 / 14$ & $8 / 30$ & N.D. & 690 & 1,050 & 1,348 & 1,650 & 1,932 \\
\hline & & 2001 & N.D. & $6 / 15$ & $7 / 3$ & $7 / 23$ & $8 / 11$ & $9 / 2$ & N.D. & 720 & 983 & 1,337 & 1,656 & 2,030 \\
\hline \multirow[t]{3}{*}{ c) } & Shizuoka & 1999 & $5 / 25$ & $6 / 11$ & $7 / 3$ & $7 / 31$ & $8 / 13$ & $8 / 29$ & 481 & 670 & 948 & 1,396 & 1,628 & 1,908 \\
\hline & & 2000 & $5 / 16$ & $6 / 11$ & - & $7 / 28$ & $8 / 8$ & $8 / 31$ & 374 & 662 & - & 1,348 & 1,544 & 1,948 \\
\hline & & 2001 & $5 / 14$ & $6 / 13$ & $7 / 2$ & $7 / 22$ & $8 / 13$ & $8 / 24$ & 364 & 700 & 968 & 1,318 & 1,692 & 1,882 \\
\hline \multirow[t]{3}{*}{ d) } & Fujieda & 1999 & $5 / 22$ & $6 / 7$ & $7 / 1$ & $7 / 26$ & $8 / 12$ & $9 / 2$ & 449 & 621 & 921 & 1,308 & 1,610 & 1,982 \\
\hline & & 2000 & $5 / 16$ & $6 / 14$ & $7 / 5$ & $7 / 25$ & $8 / 17$ & $8 / 30$ & 374 & 690 & 974 & 1,305 & 1,698 & 1,932 \\
\hline & & 2001 & $5 / 14$ & $6 / 15$ & $7 / 4$ & - & $8 / 11$ & $8 / 24$ & 364 & 720 & 1,000 & - & 1,656 & 1,882 \\
\hline \multirow[t]{3}{*}{ e) } & Haibara & 1999 & $5 / 23$ & $6 / 13$ & $7 / 3$ & $7 / 27$ & $8 / 15$ & $9 / 4$ & 459 & 696 & 948 & 1,325 & 1,661 & 2,013 \\
\hline & & 2000 & $5 / 23$ & $6 / 16$ & $7 / 8$ & $8 / 4$ & $8 / 16$ & $9 / 2$ & 439 & 714 & 1,018 & 1,471 & 1,682 & 1,985 \\
\hline & & 2001 & N.D. & $6 / 22$ & $7 / 6$ & $7 / 21$ & $8 / 13$ & $8 / 24$ & N.D. & 808 & 1,036 & 1,299 & 1,692 & 1,882 \\
\hline \multirow[t]{3}{*}{ f) } & Iwata & 1999 & $5 / 13$ & $6 / 9$ & $7 / 2$ & $7 / 25$ & $8 / 9$ & $8 / 29$ & 362 & 648 & 941 & 1,297 & 1,570 & 1,925 \\
\hline & & 2000 & $5 / 17$ & $6 / 9$ & $7 / 3$ & $7 / 20$ & $8 / 11$ & $9 / 2$ & 363 & 628 & 939 & 1,222 & 1,606 & 2,002 \\
\hline & & 2001 & $5 / 12$ & $6 / 17$ & $6 / 29$ & $7 / 22$ & - & $8 / 22$ & 341 & 748 & 926 & 1,332 & - & 1,880 \\
\hline \multirow[t]{3}{*}{ g) } & Hosoe & 1999 & $5 / 18$ & $6 / 20$ & $7 / 7$ & - & $8 / 14$ & - & 410 & 790 & 1,007 & - & 1,657 & - \\
\hline & & 2000 & $5 / 19$ & $6 / 16$ & $6 / 30$ & - & $8 / 11$ & - & 382 & 700 & 888 & - & 1,606 & - \\
\hline & & 2001 & N.D. & $6 / 18$ & $7 / 3$ & $7 / 19$ & $8 / 3$ & $8 / 19$ & N.D. & 762 & 993 & 1,277 & 1,551 & 1,831 \\
\hline \multirow[t]{3}{*}{ h) } & Mikkabi & 1999 & $5 / 18$ & $6 / 15$ & $7 / 9$ & $7 / 27$ & $8 / 18$ & $9 / 10$ & 396 & 713 & 1,031 & 1,331 & 1,727 & 2,130 \\
\hline & & 2000 & $5 / 20$ & $6 / 13$ & $7 / 9$ & $7 / 25$ & $8 / 18$ & - & 379 & 659 & 1,032 & 1,314 & 1,728 & - \\
\hline & & 2001 & $5 / 23$ & $6 / 16$ & $7 / 1$ & $7 / 19$ & $8 / 15$ & - & 456 & 706 & 936 & 1,248 & 1,734 & - \\
\hline
\end{tabular}

N.D.: not determined, — : obscure because of low occurrence.

adult immigration time in these orchards can be uniformly estimated using data from the Shimizu AMeDAS station. A positive linear relationship was also observed $\left(n=84, r^{2}=0.989, p<0.001\right)$ when data from all five orchards were pooled, and the regression line could be expressed by the following equation:

$$
y=70.67+314.92 x
$$

The regression lines differed slightly but significantly among the three orchards (Iwata, Hosoe, and Mikkabi) in the western district in terms of their slope (ANCOVA, $F=6.277, p=0.004$ ). However, the regression lines for the Iwata and Mikkabi orchards did not differ significantly in their slope, as determined from Eq. (2) (ANCOVA, $F=0.004$ and 3.610, $p=0.949$ and 0.060 , respectively). These results indicate that the intervals between generations in Iwata and Mikkabi were equal to those in the five orchards of the central district of Shizuoka Prefecture.

\section{DISCUSSION}

Tatara (1994) and Shibao (1996) investigated the occurrence of $S$. dorsalis using sticky traps in citrus orchards or vineyards at 1-week intervals, and they concluded that it was impossible to estimate the peak day by calculating the total effective temperature after the 2nd generation in June because the succeeding generations overlapped. However, other research has shown that the duration of de- 

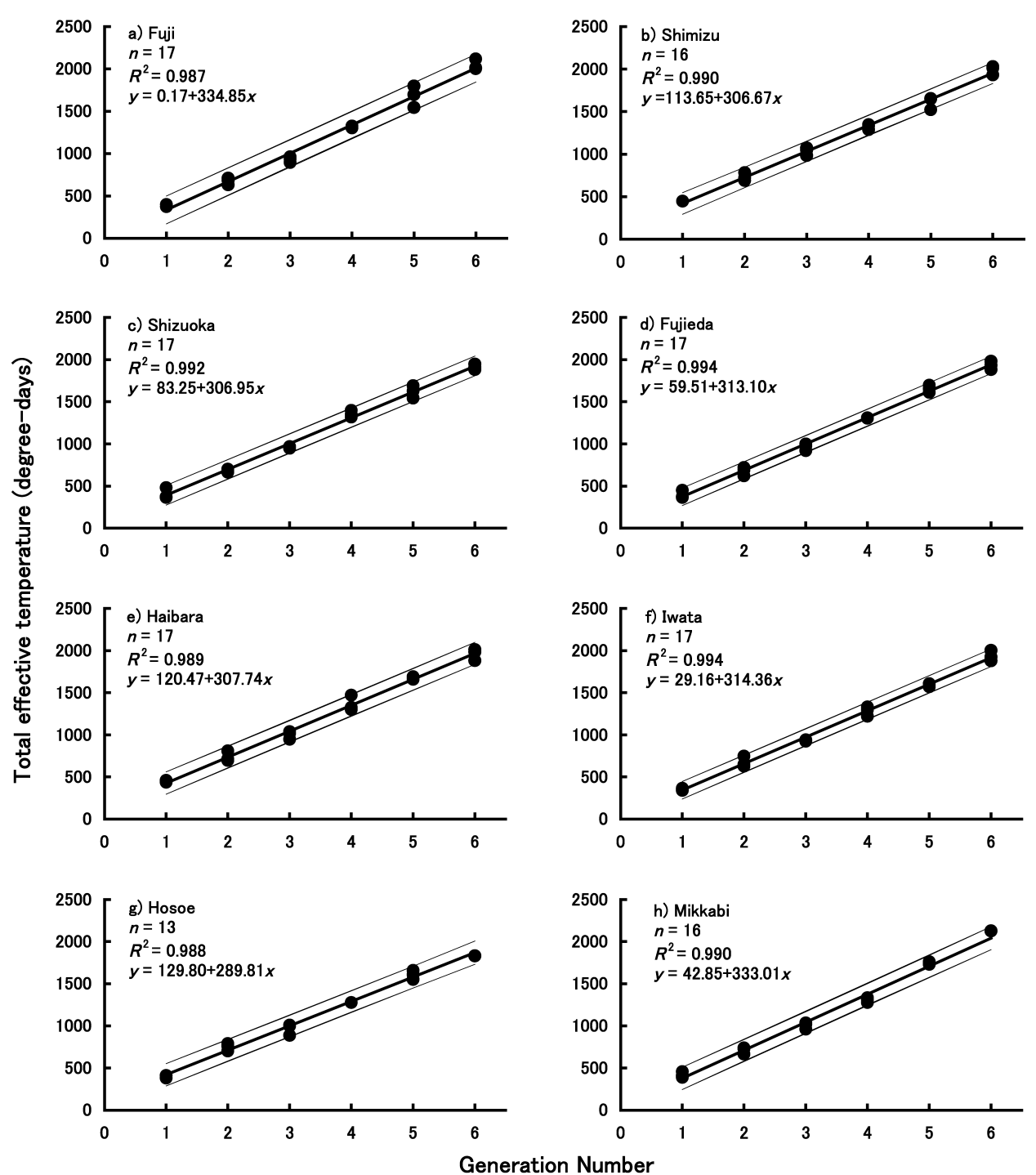

Fig. 3. Relationship between the generation number $(x)$ and the total effective temperature $(y)$ on peak days of the occurrence of $S$. dorsalis adults in the citrus orchards from 1999 to 2001 . Dotted lines indicate $95 \%$ confidence intervals.

velopment between oviposition and adult emergence was approximately 2 weeks at 29.5 or $30.0^{\circ} \mathrm{C}$ (Tatara, 1994; Shibao, 1996); this indicates that the 1-week duration between censuses was too long to detect the generations during the summer. Therefore, the estimation of each peak day using data collected every few days should be considered, as was done successfully in the present study.

Overwintering adults of $S$. dorsalis emerge from dormancy in late March (Okada and Kudo, 1982), and the 1st generation adults can be found in early May (Masui, 2007b). Adult immigration into citrus orchards reaches a peak approximately six times from early May to mid-September, and the peak time coincides with the time of adult emergence from host plants surrounding the orchards (Masui, 2007a). This study enabled estimation of the peak days of adult immigration into citrus orchards from May to September by calculating the total effective temperature and by analyzing trap data collected every few days. In addition, the results indicated that adult immigration times can be estimated simultaneously over a wide area, because the immigration times for the five citrus orchards in the central district of Shizuoka Prefecture could be uniformly estimated using data from the AMeDAS station in Shimizu. This result suggests that in the future, it will be possible to predict adult immigration times by means of real-time calculation of total effective temperature. Further, the prediction 
will permit timely control of infestations by means of insecticide application or application of the reflective sheet mulching that has also been used to control S. dorsalis (Muraoka, 1991; Tatara, 1992; Tsuchiya et al., 1995).

The slight difference in the intervals between generations observed in different orchards might be due to environmental differences such as the local ambient temperature, which affects the developmental rate, and the different shoot-elongation periods of the local vegetation, which affects the propagation of $S$. dorsalis. Thus, in some cases, meteorological observations in smaller areas (i.e., closer to each orchard) or modification of the regression equation may be required to predict the peak day of adult immigration more accurately.

The intervals (290 to 334 degree-days) between successive peaks of adult immigration that were estimated in this study were slightly larger than the total effective temperature (265 degree-days) from oviposition to adult emergence that was reported by Tatara (1994). However, this discrepancy is reasonable because the preoviposition period in $S$. dorsalis females is $1 \mathrm{~d}$, and the egg-laying period can be longer than $20 \mathrm{~d}$ at $25^{\circ} \mathrm{C}$ (Tatara, 1994). Hence, the generation number and peak days of adult occurrence can be estimated more correctly by applying the generation intervals observed in the field.

Using Eq. (2), the peak days of adult immigration for each generation could be tentatively estimated using data from the Shimizu AMeDAS station in 1993 and 1998, when the average temperatures throughout the year were the lowest and highest temperatures recorded between 1987 and 2006, respectively. On this basis, the peak days of adult immigration in the 1st generation were estimated to be May 28, 1993 and May 7, 1998; these peak days differed by $21 \mathrm{~d}$. In contrast, the peak days in the 6th generation were estimated to be September 28, 1993 and August 23, 1998; these peak days differed by a larger amount (36d). Thus, the present prediction equation may be useful to detect peak days that vary greatly among years and among generations, and to estimate the optimal timing for chemical control of $S$. dorsalis in citrus orchards.

Global warming is now occurring, and its effects on the occurrence of pest insects are receiving increased attention. Two different approaches have been applied to project the influence of global warming on insects - estimating an increase in the number of generations using a formula based on effective temperature (Yamamura and Kiritani, 1998) and examining a change in the phenology and occurrence of pests using field survey data collected in years with an unusually high temperature (Yamaguchi et al., 2001). Although the influence of global warming on $S$. dorsalis populations is presently unclear, the regression line obtained in the present study would be helpful in predicting the changes in the life cycle of $S$. dorsalis caused by global warming if census data can be related to the actual field conditions.

\section{ACKNOWLEDGEMENTS}

I thank Dr. I. Adachi, National Institute of Fruit Tree Science, for providing support and for revising early drafts of this manuscript. I also thank F. Ikeda, former Managing Director of the Shizuoka Plant Protection Center, for his valuable advice. I am grateful to the staff of each agricultural cooperative in the study area, whose assistance made this work possible. This work was partly supported by projects on plant protection from the Ministry of Agriculture, Forestry and Fisheries, Japan.

\section{REFERENCES}

Masui, S. (2007a) Synchronism of immigration of adult yellow tea thrips, Scirtothrips dorsalis Hood (Thysanoptera: Thripidae) to citrus orchards with reference to their occurrence on surrounding host plants. Appl. Entomol. Zool. 42: 517-523.

Masui, S. (2007b) Oviposition time of overwintered adults of yellow tea thrips, Scirtothrips dorsalis Hood (Thysanoptera: Thripidae). Jpn. J. Appl. Entomol. Zool. 51: 289-291 (in Japanese with English summary).

Masui, S., S. Ishigami, Y. Yamamoto, T. Isozumi, N. Ueno and $\mathrm{N}$. Inoue (1995) Role of local forecasting for occurrence of citrus pest. Plant Prot. 49: 318-321 (in Japanese).

Muraoka, M. (1990) A yellow sticky trap developed for forecasting the occurrence of the thrips in orchards. Plant Prot. 44: 24-26 (in Japanese).

Muraoka, M. (1991) Effects of ground covering by the porous water-proof film on the occurrence of the yellow tea thrips, Scirtothrips dorsalis Hood. Proc. Assoc. Plant Prot. Kyushu 37: 167-169 (in Japanese).

Nishino, M. and S. Kodomari (1988) Scirtothrips dorsalis Hood. In Pest Thrips in Japan (K. Umeya, I. Kudo and M. Miyazaki, eds.). Zenkoku Noson Kyoiku Kyokai, Tokyo, pp. 192-233 (in Japanese).

Ohkubo, N. (1989) Forecasting of occurrence of yellow tea thrips, Scirtothrips dorsalis (Hood) in a citrus producing area by yellow plate sticky trap. Proc. Assoc. Plant Prot. Kyushu 35: 142-145 (in Japanese).

Okada, T. and I. Kudo (1982) Overwintering site and stage of Scirtothrips dorsalis Hood (Thysanoptera: Thripidae) 
in tea fields. Jpn. J. Appl. Entomol. Zool. 26: 177-182 (in Japanese with English summary).

Okada, T., M. Otaishi and T. Kaneko (1981) Diurnal change in activity of adults of Scirtothrips dorsalis Hood. Study of Tea 60: 44-46 (in Japanese with English summary).

Sakakibara, N. and J. Nishigaki (1988) Seasonal abundance of the chilli thrips, Scirtothrips dorsalis Hood (Thisanoptera (sic): Thripidae) in a kiwi fruit orchard. Bull. Fac. Agric. Shizuoka Univ. 38: 1-6 (in Japanese with English summary).

Shibao, M. (1996) Effects of temperature on development of the chillie thrips, Scirtothrips dorsalis Hood (Thysanoptera: Thripidae), on grape. Appl. Entomol. Zool. 31: 81-86.

Shibao, M., F. Tanaka, R. Tsukuda and K. Fujisaki (1991) Overwintering sites and stages of the chillie thrips, Scirtothrips dorsalis Hood (Thysanoptera: Thripidae) in grape fields. Jpn. J. Appl. Entomol. Zool. 35: 161-163 (in Japanese with English summary).

Tatara, A. (1992) Reflective film as control measures for tea yellow thrips (Scirtothrips dorsalis Hood) in citrus groves. Bull. Shizuoka Citrus Exp. Sta. 24: 39-52 (in Japanese with English summary).

Tatara, A. (1994) Effect of temperature and host plant on the development, fertility and longevity of Scirtothrips dor- salis Hood (Thysanoptera: Thripidae). Appl. Entomol. Zool. 29: 31-37.

Tatara, A. (1995) Bionomics, monitoring and control of Scirtothrips dorsalis Hood (yellow tea thrips) in citrus groves. Special Bull. Shizuoka Citrus Exp. Sta. 7: 1-98 (in Japanese with English summary).

Tatara, A. and K. Furuhashi (1992) Analytical study on damage to satsuma mandarin fruit by Scirtothrips dorsalis Hood (Thysanoptera: Thripidae), with particular reference to pest density. Jpn. J. Appl. Entomol. Zool. 36: 217-223 (in Japanese with English summary).

Tsuchiya, M., K. Furuhashi and S. Masui (1995) Control of yellow tea thrips (Scirtothrips dorsalis Hood) by reflective sheet in Satsuma mandarin (Citrus unshiu Marc.) orchard. Jpn. J. Appl. Entomol. Zool. 39: 219-225 (in Japanese with English summary).

Yamaguchi, T., K. Kiritani, K. Matsuhira and K. Hukuda (2001) The influence of unusual hot weather on the occurrence of several arthropod crop pests. Jpn. J. Appl. Entomol. Zool. 45: 1-7 (in Japanese with English summary).

Yamamura, K. and K. Kiritani (1998) A simple method to estimate the potential increase in the number of generations under global warming in temperate zones. Appl. Entomol. Zool. 33: 289-298. 